\title{
Chemoenzymatic Synthesis of Apremilast: A Study Using Ketoreductases and Lipases
}

\author{
Kimberly B. Vega, ${ }^{a}$ Daniel M. V. Cruz, ${ }^{a}$ Artur R. T. Oliveira, ${ }^{a}$ Marcos R. da Silva, ${ }^{b}$ \\ Telma L. G. de Lemos, ${ }^{a}$ Maria C. F. Oliveira, ${ }^{a}$ Ricardo D. S. Bernardo, ${ }^{\oplus a}$ Jackson R. de Sousa, ${ }^{a}$ \\ Geancarlo Zanatta, ${ }^{c}$ Fábio D. Nasário, ${ }^{d}$ Anita J. Marsaiolid ${ }^{d}$ d Marcos C. de Mattos ${ }^{\circledR *, a}$ \\ ${ }^{a}$ Laboratório de Biotecnologia e Síntese Orgânica (LABS), Departamento de Química Orgânica e Inorgânica, \\ Universidade Federal do Ceará, Campus do Pici, 60455-970 Fortaleza-CE, Brazil \\ ${ }^{b}$ Instituto de Química, Universidade Federal Rio Grande do Norte, 59072-970 Natal-RN, Brazil \\ 'Departamento de Física, Universidade Federal do Ceará, Campus do Pici, 60440-554 Fortaleza-CE, Brazil \\ ${ }^{d}$ Departamento de Química Orgânica, Instituto de Química, Universidade Estadual de Campinas, \\ CP 6154, 3084-971 Campinas-SP, Brazil
}

\begin{abstract}
The key step in the chemoenzymatic synthesis of apremilast was to produce the chiral alcohol $(R)$-1-(3-ethoxy-4-methoxyphenyl)-2-(methylsulfonyl)ethanol, $(R)-3$. Two enzymatic approaches were evaluated to obtain $(R)-\mathbf{3}$, one using ketoreductases and the other lipases. Bioreduction of 1-(3-ethoxy-4-methoxyphenyl)-2-(methylsulfonyl)ethanone (2), using ketoreductase KRED-P2-D12, led to $(R)-3$ with $48 \%$ conversion and $93 \%$ enantiomeric excess (ee). Kinetic resolution of rac-1-(3-ethoxy-4-methoxyphenyl)-2-(methylsulfonyl)ethyl acetate ( $r a c-4)$, via hydrolysis reaction, with $20 \%$ of $n$-butanol, catalyzed by lipase from Aspergillus niger yielded $(R)-3$ with $>99 \% e e, 50 \%$ conversion and E-value (enantiomeric ratio) $>200$. The reaction between enantiomerically pure $(R)-3$ and 4-acetylamino-isoindol-1,3-dione (8) afforded apremilast in 65\% yield and $67 \% e e$.
\end{abstract}

Keywords: apremilast, biocatalysis, ketoreductases, lipases, enzymatic kinetic resolution

\section{Introduction}

Apremilast (Figure 1), (S)-N-(2-(1-(3-ethoxy4-methoxyphenyl)-2-(methylsulfonyl)ethyl)1,3-dioxoisoindolin-4-yl)acetamide, is a selective inhibitor of the enzyme phosphodiesterase 4 (PDE-4). It was developed by a pharmaceutical company and was approved by the US FDA (Food and Drug Administration) in 2014 and by the European agency EMA (European Medicines Agency) in 2015 for the treatment of moderate to severe active psoriasis and for psoriatic arthritis..$^{1,2}$ More recently, in 2018, the Brazilian agency responsible for sanitary surveillance, ANVISA (National Health Surveillance Agency), approved apremilast for commercialization. ${ }^{3}$ Apart from psoriasis, this drug has shown relevant versatility for the treatment of several diseases including acute lung injury, ${ }^{4}$ hidradenitis suppurativa, ${ }^{5}$ atopic dermatitis, ${ }^{6}$ recalcitrant aphthous stomatitis, ${ }^{7}$ inflammation in the heart caused by the action of doxorubicin-induced

*e-mail: mcdmatto@ufc.br
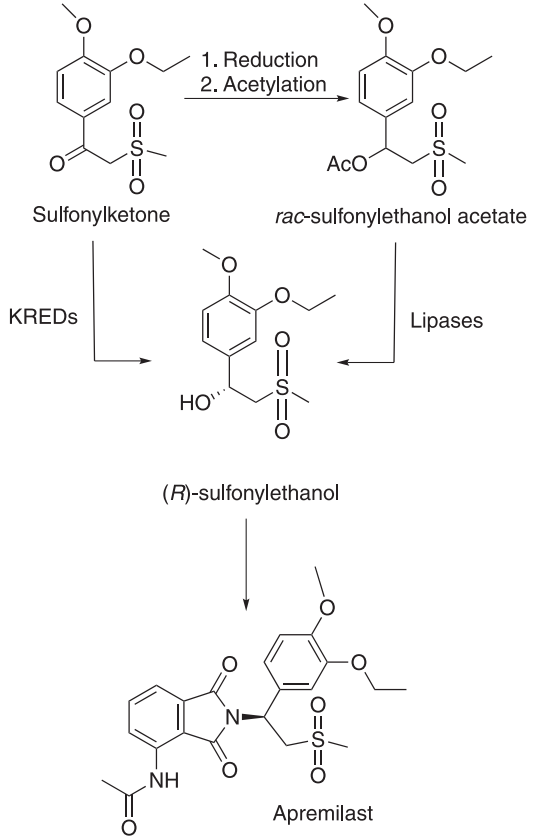

Figure 1. Chemoenzymatic approaches to produce apremilast. 
apoptosis,${ }^{8}$ recalcitrant pyoderma gangrenous 9 and Alzheimer's disease. ${ }^{10}$

Apremilast has a stereogenic center with $(S)$-configuration, being five times more active than the ent-apremilast. ${ }^{11}$ The key step of the synthesis was the kinetic resolution of $\beta$-aminosulfone 1-(3-ethoxy4-methoxyphenyl)-2-(methylsulfonyl)ethanamine using $\mathrm{N}$-acetyl-L-leucine as resolution agent, leading to the corresponding $(S)$ - $\beta$-aminosulfone with $98.4 \%$ enantiomeric excess $(e e)$. Then, the chiral $(S)-\beta$-aminosulfone reacted with 3-N-acetylaminophthalic anhydride to afford apremilast with $75 \%$ yield and $99.5 \% e e$, this obtained after recrystallization from ethanol. ${ }^{11}$

Subsequently, the same developer ${ }^{1}$ reported the synthesis of apremilast via catalytic asymmetric hydrogenation of enamine (E)-N-(1-(3-ethoxy-4-methoxyphenyl)2-(methylsulfonyl)vinyl-2,2,2-trifluoroacetamide in the presence of the rhodium catalyst $\mathrm{Rh}(\operatorname{cod})_{2} \mathrm{OTf}$ and the chiral ligand $(R, R)-\mathrm{Me}_{2}$-DuPhos, providing, after deprotection of the amine, the chiral $\beta$-aminosulfone (S)-1-(3-ethoxy-4-methoxyphenyl)-2-(methylsulfonyl) ethanamine with $68 \%$ yield and $96 \%$ ee. ${ }^{1}$ In an alternative protocol, the asymmetric hydrogenation of the enamine was carried out in the presence of the ferrocene catalyst $(S, R)-t$-Bu-Josiphos, followed by deprotection of the amine and treatment with $N$-acetyl-L-leucine. This protocol resulted the corresponding $(S)$ - $\beta$-aminosulfone with $80 \%$ yield and $99.2 \% e e .{ }^{1}$ In this same paper, ${ }^{1}$ a third option was reported for obtaining apremilast via enantioselective reduction of ketone 1-(3-ethoxy-4-methoxyphenyl)2-(methylsulfonyl)ethanone (2) through Noyori's asymmetric transfer hydrogenation. By using the ruthenium catalyst $\mathrm{RuCl}(p$-cymene) $((S, S)$-Ts-DPEN], DPEN: diphenylethylenediamine, the hydroxysulfone $(R)$-1-(3ethoxy-4-methoxyphenyl)-2-(methylsulfonyl)ethanol $(R$ 3 ) was produced with $87 \%$ yield and $99.4 \% e e$. Then, the $(R)$-alcohol underwent Mitsunobu reaction, in the presence of hydrazoic acid, being converted into the corresponding $(S)$-azide with only $41.7 \% e e$. The authors considered that the degree of racemization observed could be attributed to the formation of a carbocation from intermediate (R)-3 (an ortho- and para-alkoxybenzyl alcohol) via an $\mathrm{S}_{\mathrm{N}} 1$-type reaction. Thereafter, the conversion of $(S)$-azide into the corresponding $(S)$-amine, followed by treatment with $N$-Ac-Leu salt and crystallization, produced the corresponding salt of $(S)$ - $\beta$-aminosulfone with $94.4 \% e e .{ }^{1}$ In all these cases, the reaction between $(S)$ - $\beta$-aminosulfone and 3- $\mathrm{N}$-acetylaminophthalic anhydride led to apremilast in the enantiomerically enriched form. ${ }^{1}$

In $2017,{ }^{12}$ chiral $\beta$-acetylamino sulfide was reported to be a potential intermediary in the synthesis of apremilast.
The latter was obtained with $99 \%$ yield and $96 \%$ ee, through asymmetric hydrogenation of $N$-(1-(3-ethoxy4-methoxyphenyl)-2-(methylthio)vinyl)acetamide, in the presence of the rhodium catalyst $\mathrm{Rh}(\mathrm{NBD}){ }_{4} \mathrm{BF}_{4}$ NBD: norbornadiene, and the ligand $\left(\mathrm{S}_{c}, R_{p}\right)$-DuanPhos. After that, the chiral $\beta$-acetylamino sulfide was oxidized, in the presence of $30 \% \mathrm{H}_{2} \mathrm{O}_{2}$ and $\mathrm{TaCl}_{5}$ catalyst, to produce the corresponding $\beta$-acetylamino sulfone with $50 \%$ yield and $94 \% e e .{ }^{12}$ More recently, a new approach was reported ${ }^{13}$ for the synthesis of apremilast, which consisted of the reaction between 4-amino-2-(2-methylsulfonyl)vinyl)isoindoline1,3-dione and (3-ethoxy-4-methoxyphenyl)boronic acid, using the rhodium catalyst $\left[\mathrm{RhCl}\left(\mathrm{C}_{2} \mathrm{H}_{4}\right)_{2}\right]_{2}$ and a chiral ligand, (1S,4S)-1,7,7-trimethyl-2,5-diphenylbicyclo[2.2.1] hepta-2,5-diene or $(1 S, 4 S)$-2,5-diphenylbicyclo[2.2.1] hepta-2,5-diene. After acetylation of the amino group attached to the benzenic ring, apremilast was obtained with $94 \%$ yield and $97 \% e e .^{13}$

Biocatalysis is a powerful alternative tool to mainstream chemical synthesis to produce chiral drugs in enantioriched/enantiopure forms. This methodology has evolved to industrial application due to the ease in complementing conventional methods of synthesis of active pharmaceutical intermediates (APIs). The differential of a biocatalytic processes lies in the fact that an enzyme is obtained from renewable sources and it is biodegradable and non-hazardous, therefore being environmentally friendly. ${ }^{14}$ Conversely, the use of conventional synthetic methodologies is faced with the need to remove traces of metal catalysts such as platinum, rhodium, ruthenium, and palladium in the final stages of the process, increasing the cost of producing APIs. Biocatalytic processes can be economically more attractive, as they are generally conducted under mild conditions that include atmospheric pressure, room temperature and aqueous reaction medium, reducing waste generation. ${ }^{14}$ Moreover, the advent of direct protein evolution has enabled to tailor an enzyme to accept a specific unnatural substrate, improving catalytic performance, thermostability and stereospecificity. ${ }^{15}$ Consequently, biocatalysis is one of the main technologies endorsed by the pharmaceutical industry to produce APIs, a fact that can be proven by the large number of patents that have been granted over the last five years. Currently, approximately 300 biocatalytic processes are operating on an industrial scale. ${ }^{15-22}$

Ketoreductases (KREDs), also called alcohol dehydrogenases (ADHs) or carbonyl reductases (CRs), together with lipases, have been the most used biocatalysts at industrial scale. ${ }^{17}$ It is noteworthy that KREDs represent more than a quarter of the commercially available enzymes. This class of enzymes requires a cofactor, 
such as nicotinamide adenine dinucleotide (NADH) or its phosphorylated form (NADPH), together with a regeneration system. ${ }^{23}$ These enzymes have been widely used to produce chiral secondary alcohols, an important building block in the pharmaceutical industry to produce APIs and in fine chemistry. ${ }^{24-27}$

Lipases stand out among the enzymes used to produce APIs, since they can be used without the need of cofactor addition, besides acting on a wide range of substrates. Both factors, high abundance in nature and ease of genetic manipulation, contributed to the existence of a reasonable set of commercially available lipases. Finally, these enzymes are chemo-, regio- and enantioselective, and are generally active in organic solvent, constituting an advantage for solubilizing the organic substrate to be modified. $^{28-30}$

Herein, we report the study on the chemoenzymatic synthesis of apremilast using as key chiral intermediate a $(R)$-sulfonylethanol, Figure 1. Attempts to produce the intermediate $(R)$-sulfonylethanol involved the use of commercial KREDS and lipases from a sulfonylketone and $r a c$-sulfonylethanol acetate, respectively, Figure 1. All investigated approaches focused, especially, on the optimization of the reactional conditions.

\section{Experimental}

\section{Enzymes}

(i) Codex ${ }^{\circledR}$ Ketoreductase (KRED) screening kit was provided by Codexis (California, USA); (ii) immobilized lipases: Candida antarctica lipase type B immobilized on acrylic resin (CAL-B, Novozym 435, $7300.0 \mathrm{U} \mathrm{g}^{-1}$ ) was purchased from Novozymes ${ }^{\circledast}$ (Bischheim, France). Thermomyces lanuginosus lipase immobilized on immobead-150 (TLL, $250.0 \mathrm{U} \mathrm{g}^{-1}$ ), Amano lipase PS immobilized on diatomaceous earth (PS-IM, $\geq 500 \mathrm{U} \mathrm{g}^{-1}$ ), Amano lipase from Pseudomonas fluorescens immobilized on immobead $150\left(\geq 600 \mathrm{U} \mathrm{g}^{-1}\right)$, Amano lipase from Pseudomonas fluorescens immobilized in sol gel AK $\left(\geq 30 \mathrm{U} \mathrm{g}^{-1}\right)$, Amano lipase from Pseudomonas fluorescens immobilized in sol gel AK on pumice $\left(\geq 8 \mathrm{U} \mathrm{g}^{-1}\right)$, and Lipozyme RM IM ( $>30 \mathrm{U} \mathrm{g}^{-1}$ ) were acquired from SigmaAldrich $^{\circledR}$ (Munich, Germany); (iii) crude lipase preparations: Pseudomonas fluorescens lipase (AK, $22100.0 \mathrm{U} \mathrm{g}^{-1}$ ), Penicillium camemberti lipase ( $\left.\mathrm{G}, 50.0 \mathrm{U} \mathrm{g}^{-1}\right)$, Amano lipase PS from B. cepacia (PS, $\left.\geq 30,000 \mathrm{U} \mathrm{g}^{-1}\right)$, lipase from Rhizopus niveus ( $\mathrm{RNL}, \geq 1.5 \mathrm{U} \mathrm{mg}^{-1}$ ), Amano lipase from Mucor javanicus (MJL, $\geq 10,000 \mathrm{U} \mathrm{g}^{-1}$ ) and lipase from Aspergillus niger (ANL, $200 \mathrm{U} \mathrm{g} \mathrm{g}^{-1}$ ) were acquired from Sigma-Aldrich ${ }^{\circledast}$ (Munich, Germany). Porcine pancreas lipase (PPL, $46.0 \mathrm{U} \mathrm{g}^{-1}$ solid), and C. rugosa lipase (CRL, $1.4 \mathrm{U} \mathrm{g}^{-1}$ ) were obtained from Sigma ${ }^{\circledR}$ (São Paulo, Brazil).

\section{Chemical materials}

Chemical reagents were purchased from different commercial sources and used without further purification. Acetone, hexane, dichloromethane, chloroform, ethyl acetate, methanol and isopropanol were acquired from Biograde (Anápolis, Brazil) acetonitrile was obtained from Tedia (Anápolis, Brazil); toluene, 1,4-dioxane and dimethylsulfoxide (DMSO) were obtained from Synth (Diadema, Brazil); $n$-butanol was purchased from Dinamica (Indaiatuba, Brazil); petroleum ether was from Neon (Suzano, Brazil). High performance liquid chromatography (HPLC) grade isopropanol (IPA) and hexane were purchased from Bio Scie (Anápolis, Brazil); tetrahydrofuran (THF), heptane, cyclohexane, and methyl tert-butyl ether (MTBE) were acquired from Sigma-Aldrich (São Paulo, Brazil). Solvents were distilled over an appropriate desiccant under nitrogen. Analytical thin layer chromatography (TLC) analyses were performed on aluminum sheets pre-coated with silica gel 60 F254 (0.2 mm thick) from Merck (Darmstadt, Germany). Flash chromatographies were performed using silica gel 60 (230-240 mesh).

\section{Analysis}

Melting points were determined on a Microquimica model APF 301 (Marconi, São Paulo, Brazil) apparatus and are uncorrected. ${ }^{1} \mathrm{H}$ and ${ }^{13} \mathrm{C}$ nuclear magnetic resonance (NMR) were obtained using spectrometer Bruker model Avance DRX-300 (Billerica, USA), operating at frequency of $300 \mathrm{MHz}$ for hydrogen and frequency of $75 \mathrm{MHz}$ for carbon. The chemical shifts are given in delta $(\delta)$ values and the absolute values of coupling constants $(J)$ in hertz $(\mathrm{Hz})$. Measurement of the optical rotation was done in a PerkinElmer 341 polarimeter (Shelton, USA). Conversions and enantiomeric excesses were measured by HPLC using a Shimadzu chromatograph model LC solution 20A (Missouri, USA) with a chiral column Chiracel $^{\circledR}$ OD-H (150 m $\times 4.6 \mathrm{~mm}$ I.D.), with oven set at $40{ }^{\circ} \mathrm{C}$ for the intermediaries $\mathrm{rac}-3$ and $\mathrm{rac}-4$. For apremilast and ent-apremilast, a chiral column Chirace ${ }^{\circledR}$ IA $(150 \mathrm{~m} \times 4.6 \mathrm{~mm} \mathrm{I.D.})$ with oven set at $30^{\circ} \mathrm{C}$ was used. The injection volume was $20 \mu \mathrm{L}$ and flow was $1.0 \mathrm{~mL} \mathrm{~min}^{-1}$ using hexane:IPA (isopropyl alcohol) as eluent and UV detector. The elution conditions for the intermediates $\mathrm{rac}-\mathbf{3}$ and $\mathrm{rac}-\mathbf{4}$ were as follows: 0-41 min: gradient $95-90 \%$ hexane, 41-45 min: gradient $90-97 \%$ hexane, $45-50 \mathrm{~min}$ : gradient $97-95 \%$ hexane, $50-55 \mathrm{~min}$ : isocratic $95 \%$ 
hexane. Retention times were (207 nm): $(R)-3=31.15 \mathrm{~min}$, $(S)-3=33.86 \mathrm{~min},(S)-\mathbf{4}=36.32 \mathrm{~min} ;(R)-\mathbf{4}=41.95 \mathrm{~min}$. The elution conditions for apremilast and ent-apremilast were as follows: hexane:IPA (80:20). Retention times were $(220 \mathrm{~nm})$ : apremilast $=21.88 \mathrm{~min}$, ent -apremilast $=25.31 \mathrm{~min}$.

Gas chromatography-mass spectrometry (GC-MS) analyses were obtained on an Agilent 6890 Series GC System (Santa Clara, California, USA) and mass spectra were recorded with a Hewlett-Packard 5973 (Santa Clara, California, USA) mass selective detector (70 eV) using a fused silica capillary column (DB-5MS 5\% phenyl $95 \%$ dimethylarylene siloxane $(30 \mathrm{~m} \times 0.25 \mathrm{~mm}$ ID $\times 0.25 \mu \mathrm{m}$ film thickness) ) and helium as carrier gas $\left(1 \mathrm{~mL} \mathrm{~min}^{-1}\right)$. The injector temperature was kept at $250{ }^{\circ} \mathrm{C}$ and the detector at $280{ }^{\circ} \mathrm{C}$. The column temperature was held at $60{ }^{\circ} \mathrm{C}$ for $0.5 \mathrm{~min}$, increased to $290{ }^{\circ} \mathrm{C}$ at a rate of $25^{\circ} \mathrm{C} \mathrm{min}{ }^{-1}$, and then kept constant for $5 \mathrm{~min}$. Retention times were: ketone $2=8.93 \mathrm{~min}$, alcohol $(R)-3=9.04 \mathrm{~min}$.

Synthesis of 1-(3-ethoxy-4-methoxyphenyl)-2-(methylsulfonyl)ethanone (2)

Dimethylsulfone (926 mg, $9.85 \mathrm{mmol}$ ) and $7 \mathrm{~mL}$ of dry THF were added into a $25 \mathrm{~mL}$ flask, under nitrogen atmosphere and at $0{ }^{\circ} \mathrm{C}$. Then, a solution of $n$-butyllithium in hexane $(2.5 \mathrm{M}, 3.8 \mathrm{~mL}, 9.45 \mathrm{mmol})$ was added to the same flask. The resulting mixture was stirred at $0{ }^{\circ} \mathrm{C}$ for 1 h. Subsequently, 3-ethoxy-4-methoxybenzonitrile (1) (700 mg, $3.94 \mathrm{mmol}$ ) was dissolved in $2.3 \mathrm{~mL}$ of dry THF at $0{ }^{\circ} \mathrm{C}$ and added dropwise to the reaction mixture, maintaining this temperature for $1 \mathrm{~h}$. After this period, the temperature was raised to room temperature and the reaction system was stirred for $12 \mathrm{~h}$. After, the reaction was quenched with $6 \mathrm{~mL}$ of $2.5 \mathrm{M} \mathrm{HCl}$ solution and the mixture was stirred for $1 \mathrm{~h}$. Then, the solid formed was filtered and recrystallized from petroleum ether/EtOAc, obtaining a white solid identified as 1-(3-ethoxy-4-methoxyphenyl)2-(methylsulfonyl)ethanone (910.5 mg, 85\%) with $\mathrm{Rf}=0.47$ (hexane:EtOAc $(1: 1)$ ) and $\mathrm{mp} 144-145^{\circ} \mathrm{C}$.

Synthesis of rac-1-(3-ethoxy-4-methoxyphenyl)-2-(methylsulfonyl)ethanol (rac-3)

In a $20 \mathrm{~mL}$ flask, the ketone $2(300 \mathrm{mg}, 1.1 \mathrm{mmol})$ was dissolved in $\mathrm{CH}_{2} \mathrm{Cl}_{2}$ and $\mathrm{MeOH}(1: 4,0.1 \mathrm{M})$. Then, $\mathrm{NaBH}_{4}$ (50.1 mg, $1.32 \mathrm{mmol}$ ) was added to the flask at $0{ }^{\circ} \mathrm{C}$. After $5 \mathrm{~min}$, the temperature was raised to room temperature and the reaction system was stirred for $25 \mathrm{~min}$, followed by the evaporation of solvents under reduced pressure. Then, $10 \mathrm{~mL}$ of $1 \mathrm{M} \mathrm{HCl}$ solution was added and the product was extracted with EtOAc $(3 \times 30 \mathrm{~mL})$. The organic phase was treated with anhydrous $\mathrm{Na}_{2} \mathrm{SO}_{4}$ and, after filtration, the solvent was evaporated under reduced pressure. The crude product was purified by flash chromatographic column with flash silica gel using hexane:EtOAc (1:1) as eluent, to give a white solid identified as rac-1-(3-ethoxy4-methoxyphenyl)-2-(methylsulfonyl)ethanol, rac-3 (295 mg, 98\%), with Rf $=0.33$ (hexane:EtOAc (1:1)) and mp $115-117^{\circ} \mathrm{C}$.

Synthesis of rac-1-(3-ethoxy-4-methoxyphenyl)-2-(methylsulfonyl)ethyl acetate (rac-4)

In a $10 \mathrm{~mL}$ flask, 4-dimethylaminopyridine (DMAP) (55.7 mg, $0.456 \mathrm{mmol})$ and $\mathrm{Ac}_{2} \mathrm{O}(259.8 \mu \mathrm{L}, 2.735 \mathrm{mmol})$ were dissolved in $4 \mathrm{~mL}$ of $\mathrm{CH}_{2} \mathrm{Cl}_{2}$. Then, rac-3 $(250 \mathrm{mg}$, $0.912 \mathrm{mmol})$ and $\mathrm{Et}_{3} \mathrm{~N}(55 \mu \mathrm{L}, 0.456 \mathrm{mmol})$ were added to the flask and the reaction mixture was stirred for $1 \mathrm{~h}$. After this time, $2 \mathrm{~mL}$ of a saturated solution of $\mathrm{NaHCO}_{3}$ was added and the aqueous phase was extracted with $\mathrm{CH}_{2} \mathrm{Cl}_{2}$ $(3 \times 20 \mathrm{~mL})$. The organic phases were combined and treated with anhydrous $\mathrm{Na}_{2} \mathrm{SO}_{4}$. After filtration, the solvent was evaporated under reduced pressure and the crude product was purified by chromatographic column with flash silica gel using hexane:EtOAc $(1: 1)$ as eluent, to give the product 1-(3-ethoxy-4-methoxyphenyl)-2-(methylsulfonyl) ethyl acetate, rac-4 (246 mg, 85\%), as a white solid with $\mathrm{Rf}=0.43$ (hexane:EtOAc $(1: 1)$ ) and $\mathrm{mp}=99-100^{\circ} \mathrm{C}$.

\section{Bioreduction of ketone 2 catalyzed by KRED-P2-D12}

KRED-P2-D12 (2 mg) and ketone 2 (1.3 mg) were added in a $2 \mathrm{~mL}$ Eppendorf. Then, $25 \mu \mathrm{L}$ of ethanol and $400 \mu \mathrm{L}$ of a stock solution of KRED Recycle Mix P (composed of $125 \mathrm{mmol} \mathrm{L}^{-1}$ of potassium phosphate, $1.25 \mathrm{mmol} \mathrm{L}^{-1}$ of $\mathrm{MgSO}_{4}, 1 \mathrm{mmol} \mathrm{L}{ }^{-1}$ of $\mathrm{NADP}^{+}, 80 \mathrm{mmol} \mathrm{L}{ }^{-1}, \mathrm{pH} 7.0$ from $0.15 \mathrm{~g}$ of Mix P dispersed in $5 \mathrm{~mL}$ of Milli-Q water) were added. Subsequently, $75 \mu \mathrm{L}$ of IPA was added and the system was stirred at $180 \mathrm{rpm}$ on the orbital shaker at $30{ }^{\circ} \mathrm{C}$ for $24 \mathrm{~h}$. The reaction was quenched with the addition of $1 \mathrm{~mL}$ of EtOAc, followed by centrifugation for $5 \mathrm{~min}$ at $4500 \mathrm{rpm}$. Soon after, the organic phase was treated with anhydrous $\mathrm{Na}_{2} \mathrm{SO}_{4}$ and after filtration, the sample was analyzed in GC-MS and HPLC. After analysis, the formation of $(R)-\mathbf{3}$ was confirmed with a conversion of $48 \%$ and $93 \%$ ee.

Synthesis of $(R)-3$ and (S)-4 via kinetic resolution of rac-4 catalyzed by lipase from Aspergillus niger

A solution of acetate $\mathrm{rac}-\mathbf{4}(72.8 \mathrm{mg}, 0.229 \mathrm{mmol})$ in $2.3 \mathrm{~mL}$ of $0.1 \mathrm{M}$ phosphate buffer $\mathrm{pH} 7 / n$-butanol (8:2) (v/v) 
was prepared. Subsequently, lipase from Aspergillus niger $(3: 1 \mathrm{~m} / \mathrm{m})$ was added to the solution and the reaction mixture was stirred at $250 \mathrm{rpm}$ in the orbital shaker at $45^{\circ} \mathrm{C}$ for $6 \mathrm{~h}$. After this period, $3 \mathrm{~mL}$ of EtOAc was added to the reaction mixture, followed by centrifugation for $5 \mathrm{~min}$ at $1000 \mathrm{rpm}$. Then, the organic phase was treated with anhydrous $\mathrm{Na}_{2} \mathrm{SO}_{4}$. After filtration, the solvent was evaporated under reduced pressure and the crude product was purified by chromatographic column with flash silica gel using $\mathrm{CH}_{2} \mathrm{Cl}_{2}: \mathrm{MeOH}(9.7: 0.3)$ as eluent, to give $32 \mathrm{mg}$ of $(R)-\mathbf{3}$ $\left([\alpha]_{D}^{20}=-22^{\circ}(c 0.65\right.$, EtOAc $)$ for $\left.>99 \% e e\right)$ and $30.1 \mathrm{mg}$ of $(S)-\mathbf{4}\left([\alpha]_{D}^{20}=+55^{\circ}(c 2.33\right.$, acetone $)$ for $\left.>99 \% e e\right)$. Lit. $[\alpha]_{D}^{25}=-23.19^{\circ}(c 0.42, \mathrm{EtOAc})$ for $(R)-\mathbf{3}(>99 \% e e){ }^{31}$

\section{Synthesis of 4-nitroisoindoline-1,3-dione (6)}

In a 5 mL flask, 4-nitroisobenzofuran-1,3-dione (5) $(1.55 \mathrm{mmol}, 300 \mathrm{mg})$ and $540 \mu \mathrm{L}$ ammonia hydroxide were added. Then, a reflux condenser was adapted to the system (without water flow) and the reaction system was heated to the boiling temperature until all the water had evaporated. Thereafter, the temperature was increased to $230^{\circ} \mathrm{C}$ and heating was continued for $2 \mathrm{~h}$. After this time, a yellow solid, identified as 4-nitroisoindoline-1,3-dione (6) $(278 \mathrm{mg}, 93 \%)$, was obtained with $\mathrm{Rf}=0.61$ (hexane: EtOAc (1:1)) and mp $213-215^{\circ} \mathrm{C}$.

\section{Synthesis of 4-aminoisoindoline-1,3-dione (7)}

In a Schlenk flask, $10 \% \mathrm{Pt} / \mathrm{C}$ catalyst $(47.0 \mathrm{mg}$, $0.24 \mathrm{mmol}$ ) and $13.5 \mathrm{~mL}$ of ethanol were added. Subsequently, the nitrophthalimide $\mathbf{6}(220 \mathrm{mg}, 1.140 \mathrm{mmol})$ was added to the reaction mixture, under magnetic stirring. The reaction was maintained at an average temperature of $55^{\circ} \mathrm{C}$ and in an atmosphere of $\mathrm{H}_{2}$ at 2 atm for $24 \mathrm{~h}$. After this period, the reaction system was filtered and ethanol was evaporated under reduced pressure, yielding a green colored solid identified as 4-aminoisoindoline-1,3-dione (7) $(177.5 \mathrm{mg}, 96 \%)$, with Rf $=0.59$ (hexane:EtOAc (1:1)) and $\mathrm{mp} 265-266^{\circ} \mathrm{C}$.

\section{Synthesis of 4-acetylamino-isoindol-1,3-dione (8)}

In a $5 \mathrm{~mL}$ flask at room temperature, the aminophthalimide $7(170 \mathrm{mg}, 1.05 \mathrm{mmol})$ and acetic anhydride $(895 \mu \mathrm{L}$, $9.5 \mathrm{mmol}$ ) were added. The mixture was heated to $80^{\circ} \mathrm{C}$ and maintained under stirring for $1 \mathrm{~h}$. Then, acetic anhydride was evaporated under reduced pressure and the solid was washed with cold ethanol, filtered, and dried at room temperature. A white solid was obtained, which was identified as the 4-acetylamino-isoindol-1,3-dione (8)
(116.6 mg, 54\%), with Rf $=0.6$ (hexane: EtOAc (1:1)) and mp $236-237^{\circ} \mathrm{C}$.

\section{Synthesis of apremilast}

Triphenylphosphine ( $45.6 \mathrm{mg}, 0.174 \mathrm{mmol}$ ) and $700 \mu \mathrm{L}$ dry THF/toluene (1:1) were added into a $10 \mathrm{~mL}$ flask, under nitrogen atmosphere, and at $-5^{\circ} \mathrm{C}$. Then, diisopropyl azodicarboxylate $(27 \mu \mathrm{L}, 0.139 \mathrm{mmol})$ was added dropwise and the reaction mixture was stirred until the precipitation of a salt. Subsequently, in another flask, the alcohol $(R)-\mathbf{3}$ (32 $\mathrm{mg}, 0.116 \mathrm{mmol}$ ) and the acetylaminophthalimide $\mathbf{8}$ (23.7 $\mathrm{mg}, 0.116 \mathrm{mmol}$ ) were dissolved in $0.4 \mathrm{~mL}$ of dry THF/toluene $(1: 1)$ at $-5{ }^{\circ} \mathrm{C}$, and under nitrogen atmosphere. This solution was transferred dropwise to the reaction mixture and the system was stirred for $5 \mathrm{~h}$ at $-5{ }^{\circ} \mathrm{C}$. Then, the temperature of the reaction system was raised to room temperature and stirred for more $7 \mathrm{~h}$. After, the solvent was evaporated under reduced pressure and the crude product was purified on a chromatographic column with flash silica gel using $\mathrm{CH}_{2} \mathrm{Cl}_{2}: \mathrm{MeOH}$ (9.8:0.2) as eluent. This procedure gave $34 \mathrm{mg}$ of a white solid identified as $(S)-N$-(2-(1-(3-ethoxy-4-methoxyphenyl)2-methylsulfonyl)ethyl)-1,3-dioxoisoindolin-4-yl) acetamide (apremilast) with $65 \%$ yield, $\mathrm{Rf}=0.78\left(\mathrm{CH}_{2} \mathrm{Cl}_{2}\right.$ : $\mathrm{MeOH}(9.5: 0.5))$ and $\mathrm{mp} 175-176^{\circ} \mathrm{C}$.

\section{Results and Discussion}

Biocatalytic approach to produce the chiral $(R)$-sulfonylethanol intermediate $(R)-3$ : via KREDs and lipases

Initially, the ketone (2) was obtained from the commercially available 3-ethoxy-4-methoxybenzonitrile (1) in two steps. The first step consisted of the reaction of $\mathbf{1}$ with the dimethylsulfone carbanium formed in the presence of $n$-butyllithium, yielding the corresponding enamine. This latter was treated one-pot with a $2.5 \mathrm{M} \mathrm{HCl}$ solution to produce the ketone (2) in $85 \%$ yield (Figure 2). Two alternative routes were investigated to produce $(R)-\mathbf{3}$, one involving the reduction of ketone $\mathbf{2}$ catalyzed by KREDs (Figure 2, path A) and other by lipase-mediated hydrolysis of the $r a c$-sulfonylethanol acetate ( $r a c-4)$, Figure 2, path B.

\section{Reduction of ketone 2 catalyzed by KREDs}

Initially, ketone 2 was subjected to chemical reduction in the presence of sodium borohydride in methanol and dichloromethane, leading to hydroxysulfone $\mathrm{rac}-3$ in $98 \%$ yield (Figure 2, path B). Then, a method using GC-MS was developed to separate ketone $\mathbf{2}$ from hydroxysulfone 


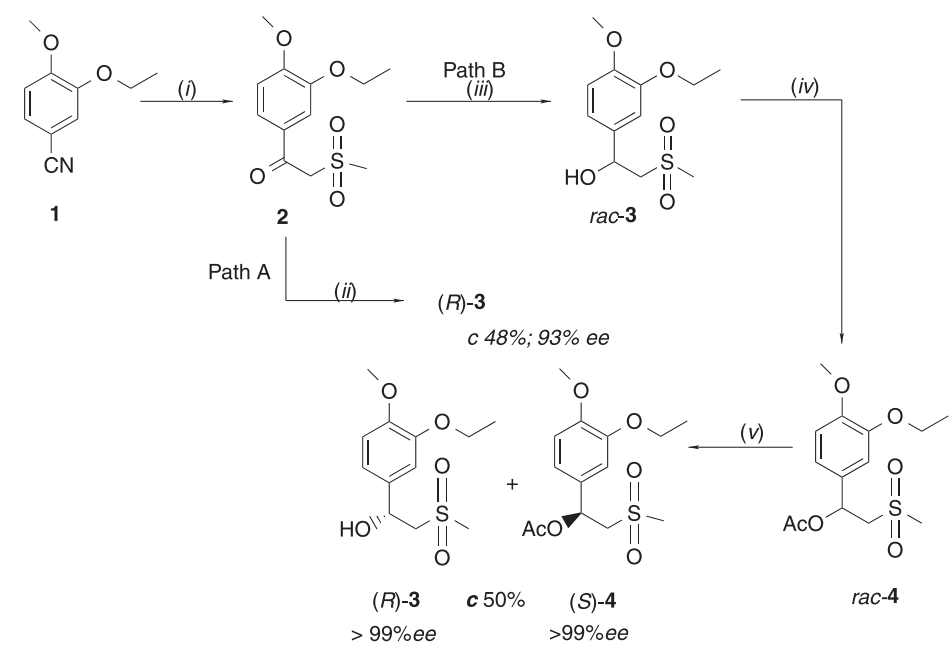

Figure 2. Chemical routes to produce the chiral sulfonylethanol intermediate $(R)-\mathbf{3}$ via reduction of ketone $\mathbf{2}$ catalyzed by KREDs (path A) or lipase-mediated hydrolysis of rac-acetate (path B). Reagents and conditions. Path A: (ii) KRED-P2-D12, NAD(P)H, EtOH; IPA, $\mathrm{H}_{2} \mathrm{O}, \mathrm{MgSO}_{4}, \mathrm{~K}_{3} \mathrm{PO}_{4}, \mathrm{pH}_{7}, 30{ }^{\circ} \mathrm{C}, 24 \mathrm{~h}$. Path B: (i) $\mathrm{Me}_{2} \mathrm{SO}_{2} / n$ - BuLi, THF; $0{ }^{\circ} \mathrm{C}$, then $\mathrm{HCl} / \mathrm{H}_{2} \mathrm{O} ; 2.5 \mathrm{M}$ (85\%); (iii) $\mathrm{NaBH}_{4}$ in $\mathrm{CH}_{2} \mathrm{Cl}_{2} / \mathrm{MeOH}, 0^{\circ} \mathrm{C}$ to r.t. (98\%); (iv) $\mathrm{Ac}_{2} \mathrm{O}, \mathrm{DMAP}$ and Et $\mathrm{N}$ in $\mathrm{CH}_{2} \mathrm{Cl}_{2}$, at r.t. (85\%); (v) lipase from Aspergillus niger, phosphate buffer pH $70.1 \mathrm{M}$ and $n$-butanol (8:2), $45^{\circ} \mathrm{C}, 6 \mathrm{~h}((R)-344 \%,>99 \% e e),((S)-445 \%,>99 \% e e)$.

rac-3, aiming to determine the conversion in the reduction reaction catalyzed by KREDs.

A screening was performed with the 24 ketoreductases from Codexis ${ }^{\circledast}$ (Codex KRED Screening Kit) using previously reported conditions. ${ }^{32}$ Ketone 2 was subjected to a reduction reaction at $30{ }^{\circ} \mathrm{C}, 24 \mathrm{~h}, 180 \mathrm{rpm}$ in the presence of a KRED with its respective cofactor recycling system and using DMSO as co-solvent (85.7\% of KRED Recycle Mix, $9.5 \%$ of IPA and $4.8 \%$ of DMSO; v:v:v). In this case, DMSO was used to solubilize ketone $\mathbf{2}$ in the reaction medium. After $24 \mathrm{~h}$ of reaction, the conversion value was determined by GC-MS analysis. Among the 24 KREDs assessed, only 8 were active. The results are summarized in Table 1. The table containing all KREDs assessed for ketone $\mathbf{2}$ reduction is found in Supplementary Information (SI) section.

Among the eight KREDs active in reducing ketone 2, only two showed anti-Prelog selectivity, leading to hydroxysulfone $(R)-\mathbf{3}$ (Table 1, entries 1 and 2). Both KRED-P2-D03 and KRED-P2-D12 produced $(R)-3$ with values of $e e>90 \%$, the latter leading to a higher conversion value $(25 \%)$. Due to this, KRED-P2-D12 was chosen for further tests with the aim of increasing the conversion of bioreduction reaction of ketone 2 . It is known that one of the advantages of the KRED-P2-D12 is the tolerance to a high amount of IPA used in the recycling of the cofactor, in the same way as the nineteen first KREDs listed in Table S1 (SI section). ${ }^{33}$ The reduction of the carbonyl group takes place under thermodynamic control and, generally, requires a large excess of IPA to favor high conversion values. ${ }^{34}$ In this way, we decided to evaluate the conversion behavior in the bioreduction of ketone $\mathbf{2}$, progressively increasing the concentration of IPA in the reaction medium with a concomitant decrease in the Recycle Mix and keeping the concentration of DMSO in $4.8 \%$. The results are summarized in Table S2 (SI section).

Table 1. Screening of commercial ketoreductases for reduction of ketone 2

\begin{tabular}{lllccc}
\hline entry & KRED & Cofactor & Cofactor recycling system & $\mathrm{c}^{\mathrm{a}} / \%$ & 25 \\
\hline 1 & KRED-P2-D12 & NADPH & isopropanol & 25 & $91(R)$ \\
2 & NADPH & isopropanol & 15 & $95(R)$ \\
3 & KRED-P2-DO3 & isopropanol & 15 & $90(S)$ \\
4 & KRED-P1-B02 & NADPH & isopropanol & 94 & $98(S)$ \\
5 & KRED-P1-C01 & NADPH & isopropanol & 90 & $48(S)$ \\
6 & KRED-P2-B02 & NADPH & isopropanol & 18 & $27(S)$ \\
8 & KRED-P2-C02 & NADPH & isopropanol & 90 & $93(S)$ \\
\hline
\end{tabular}

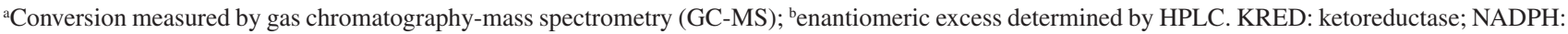
nicotinamide adenine dinucleotide in phosphorylated form. 
With the increase in IPA up to $14.3 \%$, there was an increase in conversion from 25 to $33 \%$, but concentrations above this value led to a decrease in conversion. This behavior is in line with results published in the literature. ${ }^{35}$ In addition to the DMSO, eleven more organic co-solvents were evaluated, which can modify the three-dimensional structure of an enzyme and its catalytic activity. ${ }^{35,36}$ In this case, ethanol was the most efficient co-solvent, increasing the conversion from 33 (DMSO) to $48 \%$, acting as a cosolvent, as well as a regenerating cofactor. ${ }^{37}$

Once the conditions for the reduction of ketone 2 in the presence of KRED-P2-D12 were optimized, we turned our attention to the biocatalytic approach consisted of obtaining alcohol $(R)-\mathbf{3}$ via kinetic resolution of acetate $\mathrm{rac}_{\mathbf{4}} \mathbf{4}$ by hydrolysis reaction catalyzed by lipases (Figure 2, path B).

Kinetic resolution of rac-1-(3-ethoxy-4-methoxyphenyl)2-(methylsulfonyl)ethyl acetate (rac-4) via lipase-mediated hydrolysis

First, the previously prepared hydroxysulfone $\mathrm{rac}-\mathbf{3}$ was subjected to acetylation reaction in the presence of acetic anhydride, DMAP and triethylamine in dichloromethane, providing acetate $\mathrm{rac}-\mathbf{4}$ in $85 \%$ yield. Chiral HPLC methods were developed for both $\mathrm{rac} \mathbf{- 3}$ and $\mathrm{rac}-\mathbf{4}$ to reliably measure the enantiomeric excesses of both the remaining substrate and the final product in the lipase-catalyzed resolution of rac-4.

Fifteen commercially available lipases (listed in
"Enzymes" sub-section) were evaluated in the kinetic resolution of rac-1-(3-ethoxy-4-methoxyphenyl)-2(methylsulfonyl)ethyl acetate ( $r a c-4)$ via hydrolysis reaction, Figure 2 (path B). The reactions were conducted using conditions previously reported by our research group, ${ }^{38}$ such as $1: 2$ ratio $(\mathrm{m}: \mathrm{m})$ of substrate/lipase, phosphate buffer $0.1 \mathrm{M}(\mathrm{pH} 7.0)$, acetonitrile as co-solvent (buffer/co-solvent 8:2, v:v), $30{ }^{\circ} \mathrm{C}, 250 \mathrm{rpm}$ and $24 \mathrm{~h}$. In these conditions, only the lipase from Aspergillus niger was active, leading to alcohol $(R)-\mathbf{3}$ with $93 \%$ ee and acetate $(S)-\mathbf{4}$ with $98 \%$ ee, E-value (enantiomeric ratio) of 127 and 51\% conversion (Figure 2, path B). Although we obtained promising results in the production of $(R)-3$, we decided to evaluate the behavior of this kinetic resolution in the absence of a co-solvent and in the presence of several other co-solvents. The results are summarized in Table 2.

Notably, the kinetic resolution of $\mathrm{rac}-\mathbf{4}$ in the absence of co-solvent, in just $13 \mathrm{~h}$ of reaction, reached the maximum conversion value (ca. 50\%) albeit with a low enantioselectivity value (Table 2, entry 1 ). It is known that water participates directly or indirectly in noncovalent interactions to maintain the conformation of an active enzyme..$^{39}$ In a totally aqueous microenvironment, the conformational change of the active site is highly flexible, ${ }^{40,41}$ which could provide a favorable adjustment of the two enantiomers of rac-4, leading to low enantioselectivity. The kinetic resolution of $\mathrm{rac}_{\mathbf{4}} \mathbf{4}$ in the presence of the most varied co-solvents, polar or nonpolar (with different $\log \mathrm{P}$ and dielectric constant),

Table 2. Effect of co-solvent, temperature, and enzyme:substrate ratio on the lipase from Aspergillus niger-mediated enzymatic kinetic resolution of rac-4 ${ }^{\text {a }}$

\begin{tabular}{|c|c|c|c|c|c|c|c|c|}
\hline entry & Co-solvent & $\log \mathrm{P}$ & $\varepsilon$ & time / h & $e e_{\mathrm{s}}^{\mathrm{b}} / \%$ & $e e_{\mathrm{p}}^{\mathrm{b}} / \%$ & $\mathrm{c}^{\mathrm{c}} / \%$ & $\mathrm{E}^{\mathrm{d}}$ \\
\hline 1 & none & - & - & 13 & 44 & 42 & 51 & 4 \\
\hline 2 & acetonitrile & -0.33 & 38 & 13 & 98 & 93 & 51 & 127 \\
\hline 3 & 1,4-dioxane & -0.27 & 2.21 & 24 & 98 & 87 & 51 & 60 \\
\hline 4 & isopropanol & 0.05 & 18.3 & 9 & 72 & 75 & 49 & 15 \\
\hline 5 & THF & 0.46 & 7.6 & 11 & 90 & 91 & 50 & 62 \\
\hline 6 & $n$-butanol & 0.88 & 18 & 13 & $>99$ & 96 & 51 & $>200$ \\
\hline 7 & $n$-butanol ${ }^{e}$ & 0.88 & 18 & 9 & $>99$ & $>99$ & 50 & $>200$ \\
\hline 8 & $n$-butanol ${ }^{\mathrm{f}}$ & 0.88 & 18 & 7 & 3 & 91 & 3 & 21 \\
\hline 9 & $n$-butanol ${ }^{g}$ & 0.88 & 18 & 9 & $>99$ & 98.8 & 50.3 & $>200$ \\
\hline 10 & $n$-butanol ${ }^{\mathrm{h}}$ & 0.88 & 18 & 9 & $>99$ & $>99$ & 50 & $>200$ \\
\hline 11 & $n$-butanoli & 0.88 & 18 & 6 & $>99$ & $>99$ & 50 & $>200$ \\
\hline 12 & $n$-butanol ${ }^{\mathrm{j}}$ & 0.88 & 18 & 23 & $>99$ & $>99$ & 50 & $>200$ \\
\hline 13 & MTBE & 0.94 & 2.6 & 13 & 88 & 92 & 49 & 67 \\
\hline
\end{tabular}

${ }^{\mathrm{a} C}$ Conditions: $30{ }^{\circ} \mathrm{C}, 0.1 \mathrm{M}$ phosphate buffer:co-solvent (8:2; v:v), lipase: rac-4 (2:1) at $250 \mathrm{rpm}$; ${ }^{\mathrm{b} e n a n t i o m e r i c ~ e x c e s s ~ d e t e r m i n e d ~ b y ~ H P L C ; ~}{ }^{\mathrm{c}}$ conversion,

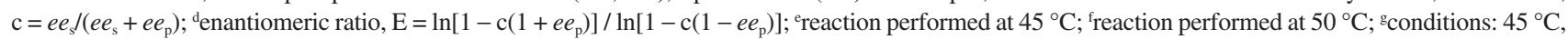

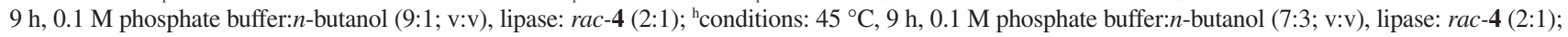
${ }^{\mathrm{i}}$ conditions: $45^{\circ} \mathrm{C}, 6 \mathrm{~h}, 0.1 \mathrm{M}$ phosphate buffer: $n$-butanol (8:2; v:v), lipase: rac-4 (3:1); ${ }^{\mathrm{j}}$ conditions: $45^{\circ} \mathrm{C}, 23 \mathrm{~h}, 0.1 \mathrm{M}$ phosphate buffer: $n$-butanol (8:2; v:v), lipase: rac-4 (1.5:1). $\log$ P: 1-octanol-water partition constant; $\varepsilon$ : dielectric constant; THF: tetrahydrofuran; MTBE: methyl tert-butyl ether. 
reached conversion values close to $50 \%$ in reaction times that varied from 9 to $24 \mathrm{~h}$ with E-values ranging from 15 to $>200$ (Table 2). Although there is no general rule that indicates the physical/chemical properties of a co-solvent that act in the alteration of enzyme activity and enantiomeric ratio, the most evaluated are $\log \mathrm{P}$ and dielectric constant. ${ }^{42-44}$ In fact, two distinct enantiomeric ratio values were obtained in co-solvents with $\log \mathrm{P}<0$, since in acetonitrile the E-value was 127 and in 1,4-dioxane it was 60 (Table 2, entries 2 and 3). This difference in enantiomeric ratio could be attributed to the ability of acetonitrile to act in the stabilization of enzyme charges, since it presents a higher dielectric constant value (38) in relation to the 1,4-dioxane dielectric constant (2.21). Among co-solvents with $\log \mathrm{P}>0$, the only one that provided a high E-value $(\mathrm{E}>200)$ was $n$-butanol (Table 2, entry 6). Apparently, $n$-butanol would be the co-solvent that presents an ideal balance between the values of $\log \mathrm{P}(0.88)$ and dielectric constant (18), enabling a high enantiomeric ratio in the performance of lipase from A. niger. Isopropanol has a dielectric constant value (18.3) like $n$-butanol (18), but a much lower $\log \mathrm{P}$ (0.05) (Table 2, entries 4 and 6, respectively). Although the analysis of $\log \mathrm{P}$ and dielectric constant are not sufficient to fully explain the behavior of co-solvents in the kinetic resolution of $\mathrm{rac}-\mathbf{4}$, it is evident that both acetonitrile (Table 2, entry 2) and $n$-butanol (Table 2, entry 6) promote a change in the microenvironment of the catalytic site of lipase from A. niger, inducing an ideal conformation for high enantiomeric ratio, especially in the case of $n$-butanol which provided an E-value $>200$.

In a few more attempts to optimize the kinetic resolution of $\mathrm{rac}-\mathbf{4}$, we decided to increase the temperature from 30 to 45 and $50{ }^{\circ} \mathrm{C}$ (Table 2, entries 7 and 8). Actually, at a higher temperature, the resolution of $\mathrm{rac}-\mathbf{4}$ occurred in a shorter reaction time and decreased from $13 \mathrm{~h}$ at $30{ }^{\circ} \mathrm{C}$ to $9 \mathrm{~h}$ at $45^{\circ} \mathrm{C}$. Surprisingly, at the same time there was an increase in the $e e$ of the product that went from $96 \%\left(30^{\circ} \mathrm{C}\right)$ to $>99 \%\left(45^{\circ} \mathrm{C}\right)$. However, at $50{ }^{\circ} \mathrm{C}$ it was possible to observe a deactivation of lipase from A. niger, since in $7 \mathrm{~h}$ of reaction the conversion was only $3 \%$ (Table 2, entry 8). A similar behavior was observed in the kinetic resolution of rac-phenylethylamines catalyzed by lipase from A. niger, whose maximum temperature for E-values $>200$ was $45^{\circ} \mathrm{C} .{ }^{45}$ In a glance analysis, it is surprising to see an increase in enzymatic enantioselectivity with increasing temperature, since in most situations the opposite occurs, enantioselectivity decreases with increasing temperature. However, there are several reports in the literature ${ }^{46-56}$ in which enzymatic enantioselectivity increases with increasing temperature. In these cases, the enantiomer is favored by entropy and the degree of flexibility at the active site of the enzyme is more evident than electrostatic and stereostatic effects. . $^{47,49,54-56}$

Since $n$-butanol showed the best performance as a co-solvent in the kinetic resolution of $\mathrm{rac}-\mathbf{4}$, we decided to investigate the influence of the amount of this co-solvent in the reaction medium, since preliminary studies were carried out in a buffer: $n$-butanol ratio of $8: 2(\mathrm{v}: \mathrm{v})$. In the 9:1 ratio ee of $(R)-3$ had a slight drop (98.8\%) and remained at $>99 \%$ in a 7:3 ratio, leading to the conclusion that $8: 2$ is the ideal buffer: $n$-butanol ratio (Table 2, entries 9 and 10 , respectively).

In this way, the addition of an ideal amount of $n$-butanol to the aqueous reaction medium and the increase in temperature from 30 to $45^{\circ} \mathrm{C}$ provided the achievement of $(R)-\mathbf{3}$ in enantiomerically pure form. It is known that in a totally aqueous medium, lipase exhibits a high flexibility ${ }^{40,41}$ and this was probably the dominate factor for the lack of enantioselectivity in the kinetic resolution of rac-4 in the absence of co-solvents (Table 2, entry 1). In the totally aqueous medium, the high flexibility of lipase from A. niger was responsible for accommodating the rac-4 enantiomers in a similar way, leading to low enantioselectivity. The addition of a co-solvent to the aqueous reaction medium with a positive $\log \mathrm{P}$ such as $n$-butanol was responsible for dramatically increasing the enantiomeric ratio (E), which went from a value of 4 to $>$ 200 (Table 2, entries 1 and 6, respectively). The addition of $n$-butanol must have caused a reduction in the flexibility of the lipase, ${ }^{57}$ altering the conformation at the active site and providing a more favorable accommodation for the $(R)-\mathbf{4}$ in detriment to its respective enantiomer, leading to a high enantioselectivity. Although the addition of $n$-butanol was responsible for dramatically increasing enantioselectivity, obtaining $(R)-\mathbf{3}$ in enantiomerically pure form was only possible when, at the same time, the temperature was increased from 30 to $45^{\circ} \mathrm{C}$ (Table 2, entry 7). In this case, the high enantioselectivity must have been caused by two distinct effects, one related to the decrease in the polarity of $n$-butanol at a higher temperature $\left(\varepsilon\left(30^{\circ} \mathrm{C}\right) 17.6\right.$ and $\left.\varepsilon\left(45^{\circ} \mathrm{C}\right) 14.7\right)$, which should cause an increase in the conformational rigidity of the enzyme (as observed in preliminary inhouse circular dichroism data, not shown) and the other related to an increase in the conformational flexibility of the enzyme by the temperature increase. These two effects act in the opposite way, but the balance between them is probably responsible for the ideal enantioselectivity observed in the kinetic resolution of rac-4.

Finally, we investigate the influence of the enzyme loading on the kinetic resolution of $\mathrm{rac}-4$. With the increase in the enzyme:substrate ratio from $2: 1$ to $3: 1$, there was a 
decrease in reaction time from 9 to $6 \mathrm{~h}$ (Table 2, entry 11). On the other hand, with the decrease in the enzyme:substrate ratio from $2: 1$ to $1.5: 1$, there was an increase in reaction time to $23 \mathrm{~h}$ (Table 2, entry 12). Therefore, the ideal rate of enzymatic loading enzyme:substrate $(\mathrm{m}: \mathrm{m})$ for the kinetic resolution of rac-4 to occur in the shortest possible reaction time is 3:1 (Table 2, entry 11).

Once our objective of obtaining $(R)-3$ in enantiomerically pure form has been achieved, we focus our attention on the synthesis of apremilast.

\section{Synthesis of apremilast}

To perform the synthesis of apremilast, it was necessary to obtain acetylaminophthalimide $\mathbf{8}$, starting from commercially available nitro anhydride 5 (Figure 3).

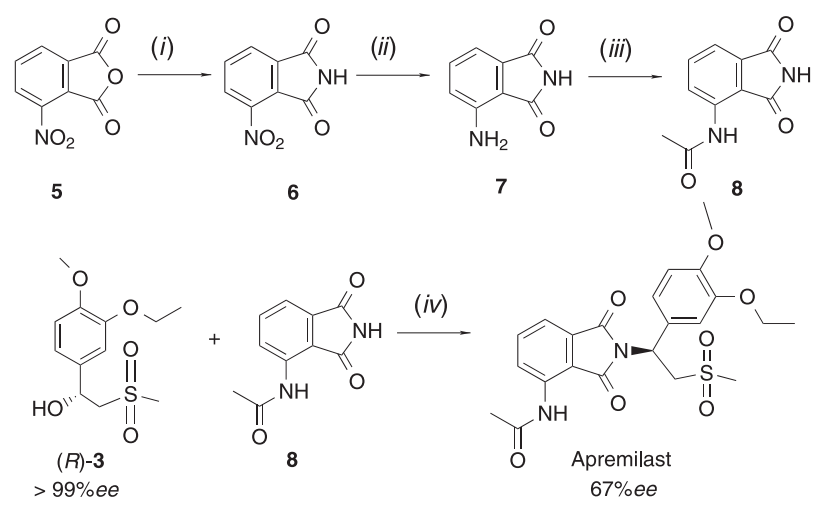

Figure 3. Synthesis of apremilast. Reagents and conditions: (i) $\mathrm{NH}_{4} \mathrm{OH}$, $230{ }^{\circ} \mathrm{C}$ (93\%); (ii) $\mathrm{H}_{2} / \mathrm{Pt} 2 \mathrm{~atm}$, EtOH, $50{ }^{\circ} \mathrm{C}$ (96\%); (iii) $\mathrm{Ac}_{2} \mathrm{O}, 80{ }^{\circ} \mathrm{C}$ (54\%); (iv) $\mathrm{PPh}_{3}$, DIAD, THF/toluene, $-5{ }^{\circ} \mathrm{C}$ to r.t. $(65 \%, 67 \%$ ee $)$.

The latter was converted to the corresponding phthalimide $\mathbf{6}$, in the presence of ammonium hydroxide and heated to $230{ }^{\circ} \mathrm{C}$, with $93 \%$ yield. Subsequently, nitrophthalimide $\mathbf{6}$ was reduced to aminophthalimide $\mathbf{7}$ in the presence of $\mathrm{Pt}$ as a catalyst, with $96 \%$ yield. In the last step, aminophthalimide 7 underwent an acetylation reaction, leading to the achievement of acetylaminophthalimide $\mathbf{8}$ with $54 \%$ yield.

Finally, apremilast could be obtained via a Mitsunobu reaction between enantiomerically pure alcohol $(R)-\mathbf{3}$ and acetylaminophthalimide $\mathbf{8}$. When the reaction was carried out using THF as solvent at $-5{ }^{\circ} \mathrm{C}$, apremilast was obtained with $65 \%$ yield and $51 \% e e$. In this case, a degree of racemization was observed during the reaction process, suggesting the reaction occurred via an $\mathrm{S}_{\mathrm{N}} 1$-type mechanism. Even so, a moderate value of enantiomeric excess was probably assured due to the formation of an intimate ion pair between the phosphonium intermediate with ortho- and para-alkoxybenzyl alcohol with a carbocation character. To enhance the formation of intimate ion pairs in the reaction medium, leading to an increase in the $e e$ of apremilast, the reaction was repeated with the addition of a more non-polar solvent, toluene. Thus, when the Mitsunobu reaction was carried out in the presence of a $1: 1(\mathrm{v}: \mathrm{v})$ mixture of toluene/THF, maintaining the temperature of the reaction medium at $-5{ }^{\circ} \mathrm{C}$, apremilast was obtained with a yield of $65 \%$ and with $67 \%$ ee (Figure 3).

\section{Conclusions}

In summary, a straightforward chemoenzymatic synthesis from apremilast was developed. Nitrile $\mathbf{1}$ was an ideal starting material as it provided both intermediates used in the two biocatalytic approaches, ketone $\mathbf{2}$ and $\mathrm{rac}-\mathbf{4}$ acetate, in high yield values. In the first approach studied, among the 24 KREDs evaluated, only two enzymes acted anti-Prelog, with emphasis on KRED-P2-D12 which led to alcohol $(R)-3$ with $48 \%$ conversion and $93 \%$ ee, using ethanol as co-solvent. Between the two biocatalytic approaches for obtaining the alcohol $(R)-\mathbf{3}$, the one that used lipases stood out compared to the one that used ketoreductases, since in this case the chiral intermediate was obtained at the maximum conversion of $50 \%$ and in the enantiomerically pure form. Lipase from A. niger has been shown to be an effective enzyme in the key stage of apremilast synthesis. It is worth mentioning that the kinetic resolution of rac-4 was only effective (conversion $50 \%$ and $\mathrm{E}>200$ ) in the presence of lipase from A. niger when the reaction was carried out in phosphate buffer medium containing $20 \%$ of $n$-butanol and when the temperature was increased from 30 to $45^{\circ} \mathrm{C}$. A plausible explanation for the increase in enantioselectivity with increasing temperature is that the preferred enantiomer in enzymatic hydrolysis, acetate $(R)-\mathbf{4}$ is favored by entropy, a phenomenon that involves changes in the conformation of the active enzyme site. Thus, a combination and a balance of factors that include an increase in enzymatic stiffness by $n$-butanol and an increase in flexibility due to temperature increase must be responsible for the lipase from $A$. niger to reach an ideal conformation for a high degree of discrimination in relation to $(R)-\mathbf{4}$.

Finally, apremilast was obtained through the Mitsunobu reaction of alcohol $(R)-\mathbf{3}$, in the enantiomerically pure form, with acetylaminophthalimide 8, resulting in $65 \%$ yield and $67 \%$ ee. Although the reaction is expected to undergo $\mathrm{S}_{\mathrm{N}} 1$-type mechanism, our data suggests that the use of a mixture of toluene:THF must have ensured a reasonable percentage of intimate ionic pairs in the reaction medium, providing apremilast with a reasonable value of $e e$. 


\section{Supplementary Information}

Supplementary data are available free of charge at http://jbcs.sbq.org.br as PDF file.

\section{Acknowledgments}

The authors thank to the Fundação Cearense de Apoio ao Desenvolvimento Científico e Tecnológico (FUNCAP) for financial support (process: DEP-016400236.02.00/19; SPU No. 1910216698), Conselho Nacional de Desenvolvimento Científico e Tecnológico (CNPq) and Coordenação de Aperfeiçoamento de Ensino Superior (CAPES) for fellowships and financial support. The authors thank the Brazilian funding agency Conselho Nacional de Desenvolvimento Científico e Tecnológico (CNPq) for providing the Special Visiting Researcher fellowship (process 400171/2014-7) under the Brazilian Scientific Program "Ciência sem Fronteira" and the research sponsorships of M. C. de Mattos (process: 306043/2018-1) and M. C. F. de Oliveira (process: 307667/2017-0). A. J. Marsaioli is thankful to CNPq for scholarship and FAPESP/ CerSusChem for financial support. The authors thank the Northeastern Center for Application and Use of NMR (CENAUREMN) for NMR spectroscopy.

\section{Author Contributions}

Kimberly B. Vega was responsible for the conceptualization, investigation, data curation, formal analysis and writing original draft; Daniel M. V. Cruz for the investigation; Artur R. T. Oliveira for the investigation; Marcos R. da Silva for the investigation and formal analysis; Telma L. G. de Lemos for the conceptualization and writing original draft; Maria C. F. Oliveira for the conceptualization, funding acquisition and writing original draft; Ricardo D. S. Bernardo for the investigation; Jackson R. de Sousa for the conceptualization and writing original draft; Geancarlo Zanatta for the conceptualization and writing original draft; Fábio D. Nasário for the investigation and formal analysis; Anita J. Marsaioli for the conceptualization, funding acquisition and writing original draft; Marcos C. de Mattos for the conceptualization, funding acquisition, writing original draft and editing.

\section{References}

1. Ruchelman, A. L.; Connolly, T. J.; Tetrahedron: Asymmetry 2015, 26, 553.

2. Nast, A.; Spuls, P. I.; van der Kraaij, G.; Gisondi, P.; Paul, C.; Ormerod, A. D.; Saiag, P.; Smith, C. H.; Dauden, E.; de Jong,
E. M.; Feist, E.; Jobling, R.; Maccarone, M.; Mrowietz, U.; Papp, K. A.; Reich, K.; Rosumeck, S.; Talme, T.; Thio, H. B.; van de Kerkhof, P.; Werner, R. N.; Dressler, C.; J. Eur. Acad. Dermatol. Venereol. 2017, 31, 1951.

3. https://panoramafarmaceutico.com.br/2018/04/11/anvisaaprova-medicamento-oral-para-psoriase-e-artrite-psoriasica/, accessed in January 2021.

4. Iman, F.; Al-Harbi, N. O.; Al-Harbi, M. M.; Qamar, W.; Aljerian, K.; Belali, O. M.; Alsanea, S.; Alanazi, A. Z.; Alhazzani, K.; Int. Immunopharmacol. 2019, 66, 260.

5. Vossen, A. R. J. V.; van Door, M. B. A.; van der Zee, H. H.; Prens, E. P.; J. Am. Acad. Dermatol. 2019, 80, 80.

6. Abrouk, M.; Farabnik, B.; Zhu, T. H.; Nakamura, M.; Singh, R.; Lee, K.; Lucking, S.-M.; Blossom, J.; Liao, W.; Koo, J.; Bhutani, T.; Shinkai, K.; Nguyen, T.; J. Am. Acad. Dermatol. 2017, 77, 177.

7. Schibler, F.; Heidemeyer, K.; Klötgen, H.-W.; Vinay, K.; Yawalkar, N.; JAAD Case Rep. 2017, 3, 410.

8. Iman, F.; Al-Harbi, N. O.; Al-Harbi, M. M.; Ansari, M. A.; AlAsmari, A. F.; Ansari, M. N.; Al-Anazi, W. A.; Bahashwan, S.; Almutairi, M. M.; Alshammari, M.; Khan, M. R.; Alsaad, A. M.; Alotaibi, M. R.; Pharmacol. Rep. 2018, 70, 993.

9. Laird, M. E.; Tong, L. X.; Lo Sicco, K. I.; Kim, R. H.; Meehan, S. A.; Franks Jr., A. G.; JAAD Case Rep. 2017, 3, 228.

10. Wu, Y.; Li, Z.; Huang, Y.-Y.; Wu, D.; Luo, H.-B.; J. Med. Chem. 2018, 61, 5467.

11. Man, H.-W.; Schafer, P.; Wong, L. M.; Patterson, R. T.; Corral, L. G.; Raymon, H.; Blease, K.; Leisten, J.; Shirley, M. A.; Tang, Y.; Babusis, D. M.; Chen, R.; Stirling, D.; Muller, G. W.; J. Med. Chem. 2009, 52, 1522.

12. Gao, W.; Lv, H.; Zhang, X.; Org. Lett. 2017, 19, 2877.

13. Syu, J.-F.; Gopula, B.; Jian, J.-H.; Li, W.-S.; Kuo, T.-S.; Wu, P.-Y.; Henschke, J. P.; Hsieh, M.-C.; Tsai, M.-K.; Wu, H.-L.; Org. Lett. 2019, 21, 4614.

14. Sheldon, R. A.; Woodley, J. M.; Chem. Rev. 2018, 118, 801.

15. Faber, K.; Fessner, W.-D.; Turner, N. J.; Adv. Synth. Catal. 2019 , $361,2373$.

16. Patel, R. N.; Bioorg. Med. Chem. 2018, 26, 1252.

17. Adams, J. P.; Brown, M. J. B.; Diaz-Rodrigues, A.; Lloyd, R. C.; Roiban, G.-D.; Adv. Synth. Catal. 2019, 361, 2421.

18. Hughes, D. L.; Org. Process Res. Dev. 2018, 22, 1063.

19. de María, P. D.; de Gonzalo, G.; Alcántara, A. R.; Catalysts 2019, 9, 802 .

20. Abdelraheem, E. M. M.; Busch, H.; Hanefeld, U.; Tonin, F.; React. Chem. Eng. 2019, 4, 1878.

21. Devine, P. N.; Howard, R. M.; Kumar, R.; Thompson, M. P.; Truppo, M. D.; Turner, N. J.; Nat. Rev. Chem. 2018, 2, 409.

22. Albarrán-Velo, J.; González-Martínez, D.; Gotor-Fernández, V.; Biocatal. Biotransform. 2018, 36, 102.

23. Wang, X.; Yiu, H. H. P.; ACS Catal. 2016, 6, 1880. 
24. Bezborodov, A. M.; Zagustina, N. A.; Appl. Biochem. Microbiol. 2016, 52, 237.

25. Sun, H.; Zhang, H.; Ang, E. L.; Zhao, H.; Bioorg. Med. Chem. 2018, 26, 1275.

26. An, J.; Nie, Y.; Xu, Y.; Crit. Rev. Biotechnol. 2019, 39, 366.

27. Chen, B.-S.; de Souza, F. Z. R.; RSC Adv. 2019, 9, 2102.

28. Carvalho, A. C. L. M.; Fonseca, T. S.; de Mattos, M. C.; de Oliveira, M. C. F.; de Lemos, T. L. G.; Molinari, F.; Romano, D.; Serra, I.; Int. J. Mol. Sci. 2015, 16, 29682.

29. Sarmah, N.; Revathi, D.; Sheelu, G.; Rani, K. Y.; Sridhar, S.; Mehtab, V.; Sumana, C.; Biotechnol. Prog. 2018, 34, 5.

30. Melani, N. B.; Tambourgi, E. B.; Silveira, E.; Sep. Purif. Rev. 2020, 49, 143.

31. Shengyin, Z.; Huang, Q.; CN105461602 (A) 2016.

32. Nasário, F. D.; Moran, P. J. S.; Rodrigues, J. A. R.; J. Braz. Chem. Soc. 2019, 30, 772.

33. García-Cerrada, S.; Redondo-Gallego, L.; Martínez-Olid, F.; Rincón, J. A.; García-Losada, P.; Org. Process Res. Dev. 2017, 21,779 .

34. Dascier, D.; Kambourakis, S.; Hua, L.; Rozzell, J. D.; Stewart, J. D.; Org. Process Res. Dev. 2014, 18, 793.

35. Guo, X.; Tang, J.-W.; Yang, J.-T.; Ni, G.-W.; Zhang, F.-L.; Chen, S.-X.; Org. Process Res. Dev. 2017, 21, 1595.

36. Petkova, G. A.; Král, V.; Biocatal. Biotransform. 2012, 30, 226.

37. Broussy, S.; Cheloha, R. W.; Berkowitz, D. B.; Org. Lett. 2009, 11,305 .

38. da Silva, M. R.; de Mattos, M. C.; de Oliveira, M. C. F.; de Lemos, T. L. G.; Ricardo, N. M. P. S.; de Gonzalo, G.; Lavandera, I.; Gotor-Fernández, V.; Gotor, V.; Tetrahedron 2014, 70, 2264.

39. Zaks, A.; Klibanov, A. M.; Proc. Natl. Acad. Sci. U.S.A. 1985 , $82,3192$.

40. Rariy, R. V.; Klibanov, A. M.; Biocatal. Biotransform. 2000, 18,401 .
41. Broos, J.; Biocatal. Biotransform. 2002, 20, 291.

42. Salihu, A.; Alam, Md. Z.; Process Biochem. 2015, 50, 86.

43. Fan, Y.; Ke, C.; Su, F.; Li, K.; Yan, Y.; Energy Fuels 2017, 31, 4372.

44. Sakai, K.; Sakurai, R.; Hirayama, N.; Tetrahedron: Asymmetry 2004, 15, 1073.

45. Pilissão, C.; Carvalho, P. O.; Nascimento, M. G.; J. Braz. Chem. Soc. 2010, 21, 973.

46. Pham, V. T.; Phillips, R. S.; J. Am. Chem. Soc. 1990, 112, 3629.

47. Phillips, R. S.; Enzyme Microb. Technol. 1992, 14, 417.

48. Lee, W. H.; Kim, K.-J.; Kim, M. G.; Lee, S. B.; J. Ferment. Bioeng. 1995, 80, 613.

49. Yasufuku, Y.; Ueji, S.-i.; Biotechnol. Lett. 1995, 17, 1311.

50. Noritomi, H.; Almarsson, O.; Barletta, G. L.; Klibanov, A. M.; Biotechnol. Bioeng. 1996, 51, 95.

51. Yasufuku, Y.; Ueji, S.-i.; Bioorg. Chem. 1997, 25, 88.

52. Yang, H.; Jönsson, Å.; Wehtje, E.; Adlercreutz, P.; Mattiasson, B.; Biochim. Biophys. Acta 1997, 1336, 51.

53. Bauer, R.; Knackmuss, H.-J.; Stolz, A.; Appl. Microbiol. Biotechnol. 1998, 49, 89.

54. Watanabe, K.; Koshiba, T.; Yasufuku, Y.; Miyazawa, T.; Ueji, S.-i.; Bioorg. Chem. 2001, 29, 65.

55. Moure, V. R.; Fabrício, C.; Frensch, G.; Marques, F. A.; Mitchell, D. A.; Krieger, N.; Biocatal. Agric. Biotechnol. 2014, 3,146 .

56. Lima, G. V.; da Silva, M. R.; Fonseca, T. S.; de Lima, L. B.; de Oliveira, M. C. F.; de Lemos, T. L. G.; Zampieri, D.; dos Santos, J. C. S.; Rios, N. S.; Gonçalves, L. R. B.; Molinari, F.; de Mattos, M. C.; Appl. Catal., A 2017, 546, 7.

57. Banik, S. D.; Nordblad, M.; Woodley, J. M.; Peters, G. H.; ACS Catal. 2016, 6, 6350.

Submitted: October 31, 2020

Published online: January 22, 2021 